Case Report:

\title{
Post-traumatic Cervical Spondyloptosis Without Neurological Deficits: A Case Report
}

Hamid Rezaee $^{1}$, Mohammad Ali Abouie-Mehrizi ${ }^{1}$ Q , Saman Mohazzab Torabi ${ }^{1}$ Q , Ehsan Keykhosravi ${ }^{{ }^{*}}$

1. Department of Neurosurgery, Shahid Kamyab Hospital, Mashhad University of Medical Sciences, Mashhad, Iran

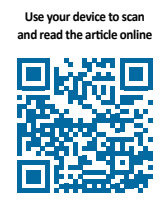

Citation Rezaee H, Abouie-Mehrizi MA, Mohazzab Torabi S, Keykhosravi E. Post-traumatic Cervical Spondyloptosis Without Neurological Deficits: A Case Report. Iran J Neurosurg. 2021; 7(3):165-170. http://dx.doi.org/10.32598/irjns.7.3.8

: http://dx.doi.org/10.32598/irjns.7.3.8

(с) 0

Article info:

Received: 06 Apr 2021

Accepted: 28 Jun 2021

Available Online: $01 \mathrm{Jul} 2021$

Keywords:

Cervical spondyloptosis, Neurological deficit, Spinal fusion, Spinal trauma

\section{A B STRACT}

Background and Importance: Traumatic cervical spondyloptosis is a rare and severe situation, i.e., associated with disabling neurological deficits.

Case Presentation: We described an unusual clinical presentation of cervical spondyloptosis in a 49-year-old man without neurological impairment and severe neck pain. Moreover, C6C7 spondyloptosis was assessed two days after the trauma. X-rays, Computed Tomography (CT) scans and Magnetic Resonance Imaging (MRI) demonstrated a C6 bi-pedicular fracture, C6-C7 facet dislocation with complete ptosis of $\mathrm{C} 6$ vertebral body over $\mathrm{C} 7$ and without spinal cord injury. The patient was managed with an intra-operative $4 \mathrm{Kg}$ traction and underwent a posterior decompression, with reduced fracture/dislocation by bilateral completed facetectomies at $\mathrm{C} 6$, and fusion from $\mathrm{C} 4$ to $\mathrm{T} 3$.

Conclusion: This case report emphasized that sometimes cervical spondyloptosis may occur without neurological deficit symptoms. Prompt clinical recognition and surgical removal are essential to prevent serious complications in this respect.

\section{* Corresponding Author:}

Address: Department of Neurosurgery, Shahid Kamyab Hospital, Mashhad University of Medical Sciences, Mashhad, Iran 


\section{Highlights}

- Traumatic Cervical spondyloptosis without neurological deficit was successfully treated with combined approach.

- Novel anterior/posterior approach is important for correcting C6-C7 spondyloptosis.

\section{Plain Language Summary}

Traumatic spinal injury due to its catastrophic outcomes has a mountable effect on the patient's quality of life and burden of diseases. Many of these kinds of trauma are related to spinal fractures which are often related to neurological deficits such as complete or incomplete spinal cord injuries. Interestingly, we reported a refereed patient from a port-town city in Iran with a history of motor vehicle accidents who was diagnosed with complete cervical C6-C7 dislocation. Although studies show that this kind of fracture often manifests with a new neurological problem, our patient presented no neurological deficit. Complete cervical dislocation is the required emergency surgical treatment, which is anterior or posterior cervical fixation. Gardner traction was applied for the patient with gradual increasing weight to achieve optimal reduction. Then, the patient underwent posterior fixation followed by anterior Cervical discectomy and fusion to achieve 360 degrees fixation.

\section{Background and Importance}

ervical spinal spondyloptosis is a catastrophic occurrence, leading to irremeable neurological deficits. Posttraumatic cervical spondyloptosis illustrates as complete cervical fracture-dislocation injuries [1]. When trauma is developed, it commonly represents an acute compression of the cervical spinal cord with various neurological impairments, i.e., often severe. Furthermore, it is often rarely irreversible even after initial or final management [2]. Thus, subaxial spine (C3-C7) cervical posttraumatic spondyloptosis without neurological deficit is very rare. The incidence of such injuries is unusual and may be due to congenital malformation [3], neoplastic disease [4, 5], and more often traumatic accident $[6,7]$. Their management is also often controversial. Reasonably, urgent surgical treatment is considered for this highly unstable type of fracture [8]. Moreover, fixation technique and the role and effectiveness of preoperative and intra-operative skull traction could be potentially hazardous in patients without neurological impairments. Herein, we reported a unique case of C6-7 spondyloptosis without neurological manifestations.

\section{Case Presentation}

A 49-year-old man was referred to Shahid Kamyab Hospital, Mahshad, from Chabahar (port-town city in south-east of Iran and nearly 1200 Km Far from Mashhad) two days after experiencing a Motor Vehicle Accident (MVA). He complained about severe neck pain and was diagnosed by simple X-Ray in a rural clinic with complete C6-C7 dislocation. Initially, the patient was admitted to our hospital with a simple rigid cervical Philadelphia collar as well as severe neck pain with limited cervical range of motion without any neurological impairment and respiratory symptoms. After the first primary control, external immobilization by the Philadelphia neck collar was fixed. Then, neck X-rays, head and neck Computed Tomography (CT) scans, and Magnetic Resonance Imaging (MRI) were taken.

CT scan data indicated a C6 bi-pedicular fracture, C6C7 facet dislocation with a complete dislocation of $\mathrm{C} 6$ vertebral body over C7 (Figure 1). Additionally, edema posterior to C6-C7 in STIR MRI view without the evidence of cord compression and spinal cord inflammation was observed.

The next day, awake intubation and positioning were performed for the patient, as we lacked neuromonitoring equipment in our center. We inserted the Gardner traction for one day with a gradual increase from 4 to $15 \mathrm{Kg}$, under direct neurovascular monitoring, achieving partial cervical realignment (Figure 2). Then, posterior decompression (C5-C7 laminectomy), with reduced fracture/dislocation by complete bilateral facetectomies at C6, and fusion from C4 to T3 were conducted. Intraoperatively, the C-ARM illustrated adequate reduction. Subsequently, on the same day, C6-C7 Anterior Cervical Discectomy and Fusion (ACDF) with anterior cage and plate was performed. 

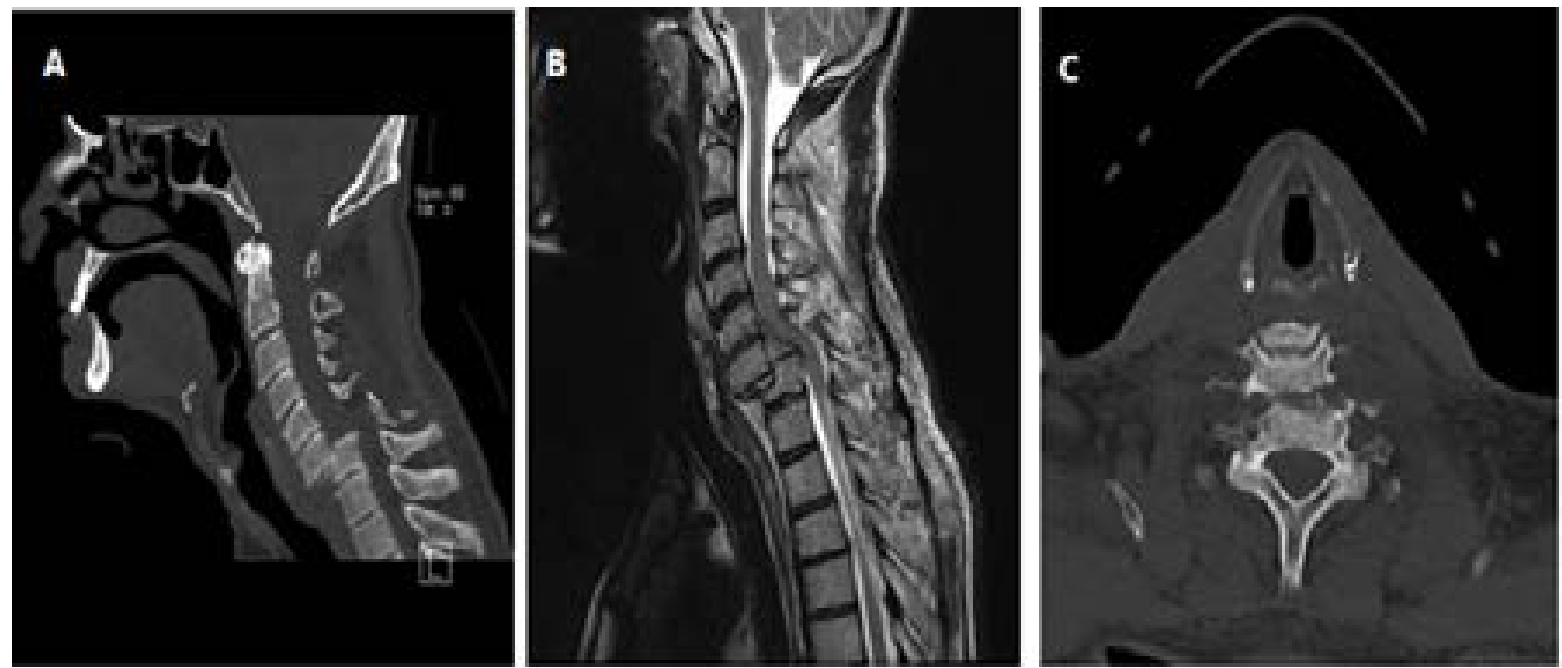

Figure 1. MRI revealing total spondyloptosis at C6-C7

Postoperative X-ray manifested no aggravation of the neurological status, and the patient was discharged neurologically intact on the third postoperative day (Figure 3). Rigid cervical orthosis was used in preoperative and postoperative periods. At a 6-months follow-up, the fusion seems stable and clinical status was satisfactory.

\section{Discussion}

Spondyloptosis refers to the completely dislocation of the vertebral body relative to the caudal. Numerous studies reported that patients with total posttraumatic spondyloptosis requiring combined anterior and posterior fixation with or without decompression [1]. Intact neurological deficits are rare in fractures of the posterior elements. The etiology in our patient was diagnosed by cervical MRI to be C6-C7 spondyloptosis after a trauma, i.e., a rare case without a neurological deficit. However, the lack of neurological manifestation may be caused by the neuroplasticity phenomenon in incomplete spinal cord injuries; it is accompanied by the alternate capacity of the neural pathway in the central nervous system [9].

Data on severe spondylolisthesis or traumatic cervical spondyloptosis without a neurological deficit are scarce [7, 10-12]. The first case of cervical posttraumatic spondyloptosis without neurological impairment was an 8-year-old girl, who was reported in 1992 by Shekha and associates. She was treated by posterior fusion alone [13]. Few cases of C6-C7 spondyloptosis were reported since 1992, dominant management in all of them was Anterior Corpectomy and Fusion (ACF) and Posterior Fu-

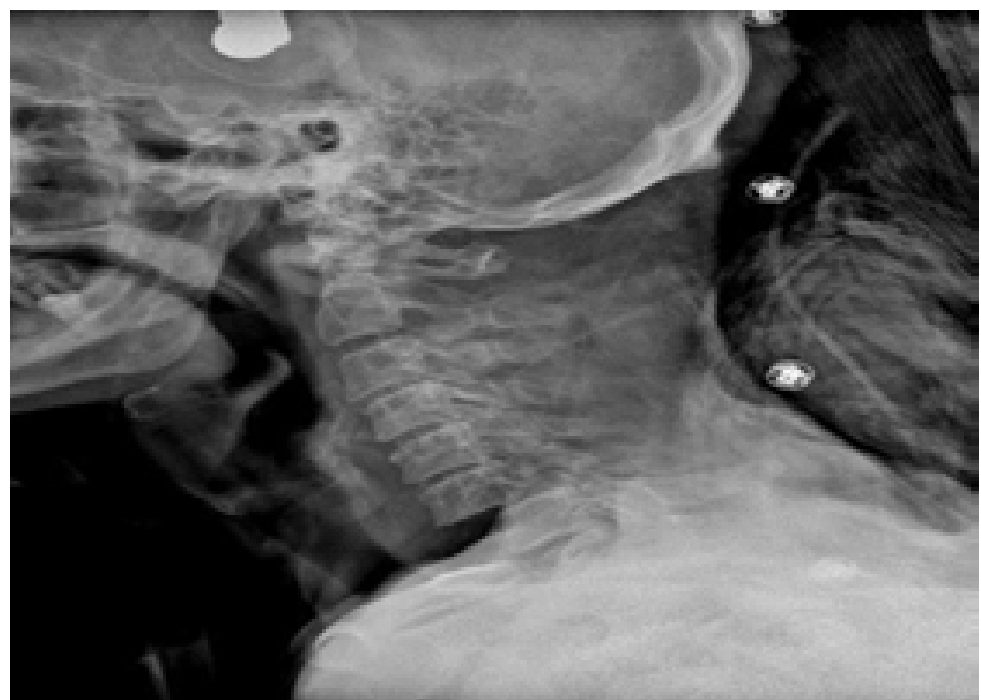

Figure 2. A lateral X-ray of the cervical spine C6-C7 was not defined 


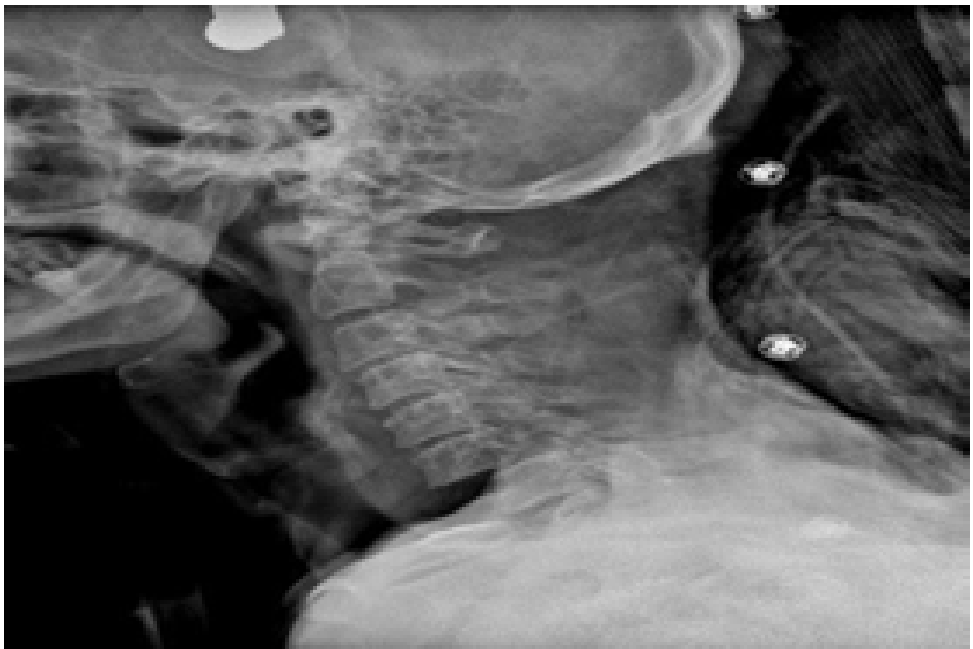

Figure 3. A: Anterior-posterior; and B: Postoperative lateral X-ray showing the physiological realignment and the correct screw placement.

sion (PF) $[7,8,13]$. Surgical methods should be used for managing this injury. The standard management for patients with reduced deformity is anterior and posterior fusion. It is suggested a posterior approach with initial decompression to widen laminectomy appears safe for patients who have not been redacted preoperatively. As we use traction on fully cardiac and nervous monitoring in the first step of the patient, Menku et al. initially performed one-stage anterior, posterior, and anterior correction of dislocated vertebrae [7].

Most of the literature advocates Physical Activity on Prescription (PAP) for patients without anterior cord compression with permanent deformity with bedside traction. The Anterior Posterior-Anterior (APA) for patients with anterior cord compression and not reduced deformity intraoperative $[14,15]$. A cervical traction of $>20 \mathrm{lb}$ for 10 days may lead to neurological damages [2]. Although the contingency of occurrence, the severe disruption of the osseoligamentous complex, highly unstable injuries is possible [2]. The most admitted worldwide approach to provide extensive canal decompression and successful cervical spine realignment is the combined anterior and posterior $360^{\circ}$ or $540^{\circ}(45 \%)$, with or without corpectomies [7, 10, 16]. Close reduction in patients with an additional rostral injury does not appear to influence the outcome and is not recommended. In awake patients before the close reduction, pre-reduction MRI is not compulsive [17].

\section{Conclusion}

The first standard management in cervical spondyloptosis is reduction and stabilization. In the event of failure reduction, early surgical decompression and an- terior and posterior stabilization should be considered to achieve early mobilization. Finally, comprehensive clinical and surgical evaluations are essential to prevent serious complications in these cases.

\section{Ethical Considerations}

\section{Compliance with ethical guidelines}

We obtained written informed consent from the patient to publish the article.

\section{Funding}

This research did not receive any grant from funding agencies in the public, commercial, or non-profit sectors.

\section{Authors' contributions}

Conception and design: Hamid Rezaie; Data collection: Hamid Rezaie, Saman Mohazzab-Torabi; Data analysis and interpretation: Hamid Rezaie, Saman MohazzabTorabi; Drafting the article: Hamid Rezaie, Saman Mohazzab-Torabi; Critically revising the article: Hamid Rezaie, Mohammad Ali Abouie, Ehsan Keikhosravi; Reviewing submitted version of manuscript: Hamid Rezaie, Ehsan Keikhosravi, Saman Mohazzab-Torabi; Approving the final version of the manuscript: Hamid Rezaie, Mohammad Ali Abouie, Ehsan Keikhosravi.

\section{Conflict of interest}

The authors declared no conflict of interest. 


\section{References}

[1] Ozdogan C, Gogusgeren M, Dosoglu M. Posttraumatic cervical spondyloptosis: Case report. Turkish Journal of Trauma and Emergency Surgery. 1999; 5:46-8. https://scholar.google. $\mathrm{com} / \mathrm{scholar}$ ?hl=en\&as_sdt $=0 \% 2 \mathrm{C} 5 \& \mathrm{q}=\& \mathrm{btnG}=$

[2] Scheer JK, Bakhsheshian J, Fakurnejad S, Oh T, Dahdaleh NS, Smith ZA. Evidence-based medicine of traumatic thoracolumbar burst fractures: A systematic review of operative management across 20 years. Global Spine Journal. 2015; 5(01):73-82. [DOI:10.1055/s-0034-1396047] [PMID] [PMCID]

[3] Wild A, Jäger M, Werner A, Eulert J, Krauspe R. Treatment of congenital spondyloptosis in an 18-month-old patient with a 10-year follow-up. Spine. 2001; 26(21):E502-5. [DOI:10.1097/00007632-200111010-00021] [PMID]

[4] Garneti N, Dunn D, El Gamal E, Williams DA, Nelson I, Sandemon D. Cervical spondyloptosis caused by an aneurysmal bone cyst: A case report. Spine. 2003; 28(4):E68-70. [DOI:10.1097/01.BRS.0000048505.19835.26] [PMID]

[5] Perlmutter DH, Campbell S, Rubery PT, Vates EG, Silberstein HJ. Aneurysmal bone cyst: Surgical management in the pediatric cervical spine. Spine. 2009; 34(1):E50-3. [DOI:10.1097/ BRS.0b013e31818a26c0] [PMID]

[6] Chadha M, Singh AP, Singh AP. Spondyloptosis of C6-C7: a rare case report. Chinese Journal of Traumatology (English Edition). 2010; 13(6):377-9. [PMID]

[7] Menku A, Kurtsoy A, Tucer B, Oktem I, Akdemir H. The surgical management of traumatic $\mathrm{C} 6-\mathrm{C} 7$ spondyloptosis in a patient without neurological deficits. Minimally Invasive Neurosurgery. 2004; 47(04):242-4. [DOI:10.1055/s-2004-818496] [PMID]

[8] Gasco J, Dilorenzo DJ, Patterson JT. C4-C5 post-traumatic spondyloptosis with in situ fusion: Systematic literature review and case report. Spine. 2013; 38(10):E621-5. [DOI:10.1097/ BRS.0b013e31828a32b4] [PMID]

[9] Lynskey JV, Belanger A, Jung R. Activity-dependent plasticity in spinal cord injury. Journal of Rehabilitation Research and Development. 2008; 45(2):229-40. [DOI:10.1682/ JRRD.2007.03.0047] [PMID] [PMCID]

[10] Mamindla RK, Kumar A, Bhattacharjee S, Sahu BP. A novel case of "ambulatory" cervical spondyloptosis: Case report with literature review. European Spine Journal. 2014; 23(2):161-6. [DOI:10.1007/s00586-013-2827-0] [PMID]

[11] Acikbas C, Gurkanlar D. Post-traumatic C7-T1 Spondyloptosis in a patient without neurological deficit: A case report. Turkish Neurosurgery. 2010; 20(2):257-60. [DOI:10.5137/10195149.JTN.1991-09.3] [PMID]

[12] Ramieri A, Domenicucci M, Cellocco P, Lenzi J, Dugoni DE, Costanzo G. Traumatic spondylolisthesis and spondyloptosis of the subaxial cervical spine without neurological deficits: Closed re-alignment, surgical options and literature review. European Spine Journal. 2014; 23(6):658-63. [DOI:10.1007/ s00586-014-3560-z] [PMID]

[13] Bhojraj SY, Shahane SM. Posttraumatic cervical spondyloptosis at C6-7 with late-onset cord compression: A new clinical entity: Case report. Journal of Neurosurgery. 1992; 77(5):792-4. [DOI:10.3171/jns.1992.77.5.0792] [PMID]
[14] Mata-Gómez J, Ortega-Martínez M, Valencia-Anguita J, Gilete-Tejero I, Royano-Sánchez M. Treatment of chronic traumatic C7-T1 grade III spondylolisthesis with mild neurological deficit: Case report. Journal of Spine Surgery. 2017; 3(1):826. [DOI:10.21037/jss.2017.02.10] [PMID] [PMCID]

[15] Chestnut RM. Early assessment, transport and management of patients with posttraumatic spinal instability. Neurological Topic AANS. 1994; 1. https://ci.nii.ac.jp/ naid/10004782735/

[16] Munakomi S, Bhattarai B, Cherian I. Traumatic cervical spondyloptosis in a neurologically stable patient: A therapeutic challenge. Case Reports in Critical Care. 2015; 2015:540919 [DOI:10.1155/2015/540919] [PMID] [PMCID]

[17] Gelb DE, Hadley MN, Aarabi B, Dhall SS, Hurlbert RJ, Rozzelle CJ, et al. Initial closed reduction of cervical spinal fracture-dislocation injuries. Neurosurgery. 2013; 72(Suppl 2):73-83. [DOI:10.1227/NEU.0b013e318276ee02] [PMID] 
This Page Intentionally Left Blank 